\title{
El Bronce Final en Huelva. Una visión preliminar del poblamiento en su ruedo agrícola a partir del registro arqueológico de La Orden-Seminario
}

\author{
Late Bronze Age at Huelva. A preliminary view of settlement patterns in \\ its chora throught the study of the archaeological record of the Orden \\ Seminario site
}

\author{
Francisco Gómez Toscano*, José Manuel Beltrán Pinzón **, \\ Diego González Batanero***, Juan Carlos Vera RodríGUez ${ }^{* * * *}$ \\ * Departamento de Historia I, Facultad de Humanidades, Campus de El Carmen, Universidad de Huelva, \\ Avda. Tres de Marzo s/n, 21007 Huelva. fgomez@uhu.es \\ **Biblioteca Universitaria, Campus de El Carmen, Universidad de Huelva, \\ Avda. Tres de Marzo s/n, 21007 Huelva.jmanuel.beltran@biblio.uhu.es \\ ***Ánfora Grupo, Avda. Alameda Sundheim 28, $7^{\circ}$ E, 21003 Huelva. diego@anforagip.com \\ ****Departamento de Historia I, Facultad de Humanidades, Campus de El Carmen, Universidad de Huelva, \\ Avda. Tres de Marzo s/n, 21007 Huelva. vera@uhu.es
}

Recibido: 30-04-2013

Aceptado: 23-03-2014

\section{RESUMEN}

De acuerdo con los resultados de la excavación de una parte de las estructuras arqueológicas registradas en el sitio La Orden-Seminario, en la periferia de la ciudad de Huelva, se presenta una síntesis preliminar relacionada fundamentalmente con la evolución histórica del asentamiento entre finales del II Milenio y la primera mitad del siguiente. La superposición en un amplio espacio de estructuras de habitación y huellas de cultivo muestran la complejidad de la sociedad del Bronce Final en el entorno agrícola del Puerto de Huelva.

Palabras Clave: Cabañas Protohistóricas, Huellas de Cultivo, Bronce Final, Huelva, España.

\begin{abstract}
In accordance with archaeological data partially obtained after the excavations conducted at La Orden-Seminario archaeological site at Huelva, a preliminary synthesis of historical evolution of the Atlantic Port as from the end of 2 nd Millennium BC to first half of following 1st Millennium BC is hereby explained. The archaeological data confirms the complexity of western Bronze Age society that inhabited agricultural surroundings of Huelva Port hereby demonstrated through their pithouses and field systems archaeological context.
\end{abstract}

Key words: Protohistorical Pithouses, Field Systems, Late Bronze, Huelva, Spain. 


\section{Introducción al Bronce Final en el Suroeste peninsular}

El Suroeste peninsular, entendido como el espacio físico comprendido al sur entre Gibraltar al este y San Vicente al oeste, y con su límite norte caracterizado hacia el interior por los tramos bajos de los ríos Guadiana y Guadalquivir como hitos geográficos más relevantes, representa un territorio muy interesante donde estudiar el desarrollo de la sociedad occidental en las postrimerías de la Prehistoria Reciente. Durante el final de la Edad del Bronce, entre los siglos finales del II Milenio a.C. y los primeros del siguiente, se han documentado en esta zona productos, ideas y técnicas concretados en elementos materiales exógenos procedentes tanto del Atlántico como del Mediterráneo, por situarse precisamente en el punto de inflexión entre ambos mundos. Por ello, al igual que otras zonas continentales europeas, pero quizá con mayor intensidad si exceptuamos algún territorio insular, el Suroeste ibérico no fue ajeno a tempranos cambios influidos por causas relacionadas principalmente, aunque no de forma exclusiva, con esos estímulos externos. Como está ampliamente constatado, en la esfera puramente tecnológica adquirirá especial relevancia un nuevo material, la aleación cobreestaño, que marcará una clara diferencia respecto a momentos anteriores, entre otras cuestiones por la necesidad de obtener recursos de otros ámbitos ajenos, incluso extrapeninsulares.

Esas intensas relaciones exteriores definidas a partir de evidencias arqueológicas confirman, entre otros múltiples aspectos, que la sociedad local establecida en el Suroeste jugó durante varios siglos el papel de intermediaria entre ambas zonas, un hecho que con el tiempo tendría una gran repercusión en los desarrollos tecnológicos, económicos y políticos entre otros niveles de aculturación para la sociedad protohistórica posterior. Si bien esto puede ser generalizado para la sociedad "orientalizante" a partir de un determinado momento del siglo VIII a.C. sin que por ello deba considerársela una sociedad conformada exclusivamente a partir de influjos foráneos, sino que con toda lógica comparativa la mayor parte de su desarrollo se deberá al peso de su capacidad endógena, especialmente en los siglos precedentes, como en otras zonas de la Europa de la Edad del Bronce (Kristiansen y Larsson 2006).

Dentro de este espacio territorial, la Tierra Llana de Huelva ha sido vinculada en general con el Bajo Guadalquivir y con el sur de Portugal en el período en que la sociedad occidental estuvo inmersa en ese mundo común representado por el período histórico-arqueológico que denominamos
Bronce Final, que en sus últimas fases daría lugar a la conclusión de la Prehistoria reciente con la adopción de formas culturales mediterráneas generalizadas. Aunque es posible existan diferencias locales, el hecho de no haberse documentado previamente asentamientos del denominado Bronze do Sudoeste establecido por H. Schubart (1971; 1975) en la década de los setenta, ni tampoco sus enterramientos en cista, hasta ahora había mantenido vigente una duda a partir de argumentos ex silentio acerca de la existencia o no de población entre las últimas manifestaciones de la Edad del Cobre y un corto período de ocupación del Bronce Final previo a la presencia de los primeros fenicios de la Edad del Hierro, que implicaba un desfase de continuidad poblacional durante todo el II Milenio a.C. Desde interpretaciones de corte marcadamente difusionista, que han vuelto a repuntar en la presente década obviando parte de la investigación más reciente, se estimaba que el Bronce Final tenía que ser algo nuevo y lógicamente exótico, una manifestación cultural que solo alcanzaría una amplia extensión territorial y poblacional a partir de la presencia de las colonias orientales del siglo VIII a.C.

A este respecto, cabe recordar que desde hace décadas se habían confirmado para momentos previos de la Edad del Bronce algunas evidencias de ocupación en zonas situadas en el reborde sur del Andévalo cercanas a Huelva (Amo 1975) y en el extremo más oriental de la propia Tierra Llana (Fernández et al. 1976), pero no con la densidad contrastada más al norte y de ahí la duda metodológica. Actualmente contamos con nuevos datos funerarios de similar cronología localizados en el propio yacimiento de La Orden-Seminario (Martínez y Vera e.p.).

A pesar de ello, el pretendido vacío poblacional hasta la colonización fenicia ha sido utilizado desde finales del pasado siglo para sobredimensionar la importancia en el desarrollo general de Occidente por impulsos exógenos, tanto de los orientales denominados fenicios como de lo que se define como Bronce Atlántico (Escacena 1995) y también está siendo defendido últimamente para explicar una posible relación entre la Tarsis bíblica y el Puerto de Huelva, el emporio occidental por definición, que solo se entiende como una primera fundación oriental negando el peso de la sociedad occidental incluso en la conformación previa del lugar (González de Canales et al. 2004).

Sin embargo, como uno de nosotros ha argumentado (Gómez 2006), precisamente la Tierra Llana de Huelva habría estado ampliamente poblada por la sociedad occidental a lo largo de su desarrollo desde los últimos siglos del II Milenio a.C., pero 
sin ningún hiato poblacional provocado por una crisis climática según ya se estimaba a finales de la década de los ochenta del pasado siglo (Díaz del Olmo 1989). Así, la continuidad poblacional pudo ser establecida a partir de las evidencias obtenidas en los sitios de Huelva (Gómez 2009), Niebla (Campos et al. 2006) y Aznalcóllar (Hunt 2003), auténticos centros hegemónicos de otros poblados de cabañas situados en su entorno más inmediato, que tal vez deberíamos definir como aldeas agropecuarias o al menos como asentamientos de pequeña entidad y sin murallas los cuales estuvieron vinculados política y económicamente a los primeros (Gómez 2006). Aznalcóllar, con los sitios amurallados de El Castillo y Los Castrejones, situados ambos en el coto minero más meridional del Cinturón Ibérico de Piritas donde se explotó cobre primero y plata desde el II Milenio a.C. (Carretero et al. 2010; Gómez e.p.); Niebla, por su situación, como controladora desde sus murallas del vado en el río Tinto y de los flujos entre las minas y la costa (Campos, Gómez y Pérez, 2006); y Huelva como el Puerto Atlántico por excelencia desde los siglos finales del II Milenio a.C., conformaron un esquema de sociedad prácticamente urbana que se relaciona con la importancia y complejidad de la sociedad local y sus relaciones con el mundo exterior (Gómez 2006; 2009; 2012).

En el puerto de Huelva específicamente, la existencia de una importante fase ocupacional de la Edad del Bronce fue rápidamente asumida desde las primeras décadas del siglo XX a partir del famoso Hallazgo de la Ría de Huelva (Ruiz-Gálvez 1995), que a mediados de los años noventa, por su manifiesta antigüedad y alguna línea de investigación vigente en esos momentos (Belén y Escacena 1995), parecía no tener relación con las amplias evidencias estimadas ya en el Cabezo de San Pedro desde la década de los sesenta y setenta del pasado siglo (Blázquez et al. 1970; Belén et al. 1978; Blázquez et al. 1979; Ruiz-Mata et al. 1981).

Como importante referencia que justifica ahora el debate, la cronología que debe estimarse para el hallazgo de la Ría de Huelva, de acuerdo con el conjunto de evidencias en el mundo mediterráneo en general, debe situarse entre los años 1050 y 950 a.C. en términos calendáricos absolutos (Torres 2008), es decir, a caballo entre ambos milenios y por ello muy anterior a la establecida por M. Almagro Basch (1957) a partir de la cronología que entonces se estimaba para las fíbulas de codo, o por M. Almagro Gorbea (1977) en este caso y lógicamente en esos momentos del final de la década de los años setenta a partir de análisis radiocarbónicos sin calibrar. Además, esta nueva estimación cronológica se muestra acorde con la reciente perspectiva en que debe integrarse al modelo de espadas tipo Huelva, que no representa el final de las de tipo atlántico de 'lengua de carpa', sino que su desarrollo depende de talleres locales andaluces desde el siglo XI a.C. (Brandherm 2007: 86).

A pesar de este importante hito cronológico, los inicios de la ocupación del Bronce Final en Huelva siguen siendo todavía puestos en duda porque los resultados que se mostraron en la primera publicación de 1970 sobre los materiales cerámicos del Cabezo de San Pedro fueron obtenidos en la limpieza de un talud que realmente no fue realizada con metodología estrictamente arqueológica. Los materiales analizados procedían de una extracción selectiva y aleatoria, por supuesto no exhaustiva, del registro observado en esa limpieza, y por esos motivos muy limitada (Gómez y Campos 2008). No está de más recordar que estas circunstancias son un indicio de que, al menos para los inicios del período, la tipología local no estaba suficientemente aclarada (Ruiz-Mata 1979; 1995), como se verá a continuación y también ha podido explicar en otro momento uno de los firmantes (Gómez 2008 y 2012; Ruiz-Mata y Gómez 2008).

Como en la publicación de las excavaciones sistemáticas posteriores los materiales del Bronce Final aparecieron, bien en estratigrafías conformadas a partir de procesos postdeposicionales (Gómez et al. 2007), o bien que en cada uno de los cortes estratigráficos no se llegase a alcanzar el sustrato estéril (Blázquez et al. 1979; Ruiz-Mata et al. 1981), parece claro que el complejo cerámico de la Fase I de Ruiz Mata (1979), que se estimó como el inicio de la ocupación en el lugar, no puede representar estrictamente a la cultura material de la ocupación más antigua del Cabezo de San Pedro, sino que faltan las formas previas que dieron lugar a las reconocidas como pertenecientes a esa Fase I (Gómez 2008; Ruiz-Mata y Gómez 2008), y mucho menos que la Fase I del Cabezo de San Pedro y su cronología inicial tengan que hacerse extensivas todavía a Huelva y al resto de los sitios del Bronce Final del Suroeste. Debe recordarse aquí que a finales de los años sesenta no se tenía referencia clara para estimar que algunas formas allí localizadas fuesen más antiguas sino que todas se incluyeron en un único período (RuizMata 1979), aunque prudentemente se dejara para más adelante establecer la tipología de las formas más antiguas (Ruiz-Mata 1995: 281).

De hecho, en la primera publicación de 1970, para representar al Nivel 6, se seleccionaron formas cerámicas bastante completas pero que perduraban en los Niveles 5a-b (Blázquez et al. 1970: Lám. XXX). El proceso de evolución diacrónica de esas formas cerámicas locales pudo producirse 
de forma distinta según podrá contrastarse ahora a partir de los datos estratigráficos obtenidos del relleno de estructuras de "vida corta" excavadas en el ruedo agrícola de Huelva, como se verá más adelante. Desde ese punto de partida puramente tipológico, a pesar de otras evidencias y en contra de explicaciones histórico-arqueológicas fundamentadas a partir de otros indicadores (Gómez 1998), muchos han dudado que en la propia Huelva existiese una sociedad compleja y dinámica conformada desde los siglos finales del II Milenio a.C. al igual que en el conjunto del Suroeste en general y de la Tierra Llana en particular.

No obstante, lo fundamental del debate acerca de la amplitud cronológica del final de la Edad del Bronce únicamente ha podido mantenerse a causa de un claro error metodológico que todavía permanece vigente, tal vez por comodidad o por mantener reconstrucciones históricas ligadas al paradigma colonial. Hace más de una década (Gómez 1998), uno de nosotros llamaba la atención sobre la incidencia que para la explicación del proceso histórico en general representaba la obsoleta cronología que seguía manteniéndose desde los años sesenta cuando se trataban de explicar los inicios de la última fase de la Edad del Bronce en el Suroeste Peninsular, a pesar de los datos empíricos ya existentes. En realidad, la teórica evolución cultural representada por la sucesión Bronce PlenoBronce Tardío-Bronce Final-Edad del Hierro no estaba representada en todos los sitios excavados, ni tampoco había lugar para incluir el paradigmático Bronce Atlántico, del que solo se conocían y mencionaban sus bronces, a pesar de que Huelva está situada en el Atlántico.

Así, como síntesis del poblamiento del final de la Edad del Bronce en el II milenio a.C., de acuerdo con los datos existentes, en la citada monografía ya se adelantaba hace años que

...el final de la Edad del Bronce se manifiesta, tal vez sin cortes ni vacíos poblacionales anacrónicos, a partir de un sustrato anterior que puede ser del final del Cobre, con o sin campaniforme, del Bronce del Sudoeste o Bronce Pleno con alta, escasa o nula representación de elementos del Horizonte Cogotas I o Bronce Tardío, pero también en asentamientos donde los elementos definitorios del Bronce Final responden a su primera ocupación. Aunque desde la aparición de las primeras evidencias del Bronce Final parece que se origina una cierta tendencia a la homogeneización de la cultura material entre los siglos finales del II Milenio a.C. y los primeros del siguiente, constatada en múltiples y diversas formas de ocupación del territorio, ello no lleva implícito que su evolución posterior sea también, en cierta forma, homogénea, ni que los procesos de cambio posteriores que darán lugar al período orientalizante se produzcan de forma sincrónica (Gómez 1998: 267).
En síntesis, si los inicios del Bronce Final solo hubiesen comenzado después de un hiato poblacional difícilmente explicable, o en momentos muy cercanos a la presencia fenicia en los centros costeros, existiría un gran contraste entre cómo se interpreta el Bronce Final en el Bajo Guadalquivir - por la gran expansión que alcanzaría la sociedad occidental en el conjunto del Suroeste según confirmaron datos posteriores (Fig. 1)-, y cómo es conocido en el entorno del Guadiana Medio, tanto en Portugal (Monge 2005; Antunes et al. 2012) como en la Extremadura española (Pavón 1998; Jiménez y Guerra 2012; Vilaça et al. 2012), o en la propia Sierra de Huelva (Gómez 1998; García 1999; Hurtado 2007; Hurtado et al. 2011), zonas que ahora son bien conocidas y ha sido demostrada su antigüedad desde el II Milenio con el apoyo de dataciones de $\mathrm{C} 14 \mathrm{y}$, en muchos casos, como continuidad del Bronce Pleno.

Si entendemos que en esas zonas del Bajo y Medio Guadiana, así como en el Sureste en general, la transición entre el Bronce Pleno y el Bronce Final habría sido plenamente demostrada (Aubet 1998) sin hiatos que hubiesen interferido en la continuidad de la población, el proceso debería haber sido muy similar tanto en la Tierra Llana de Huelva (Gómez 2006) como en el Bajo Guadalquivir y en Cádiz (Ruiz-Mata y Gómez 2008). Realmente la crisis poblacional del II Milenio y los primeros siglos del I Milenio a.C. nunca existió. El hiato solo surgió por falta de investigación y se consagró por la comodidad de trabajar con esquemas conformados hace años por nuestros maestros, que prácticamente se quieren mantener sin un debate que paulatinamente enriquezca el resultado de la investigación posterior.

De hecho, la revisión de los datos empíricos existentes en el Bajo Guadalquivir (Gómez 1998) y especialmente en la Tierra Llana de Huelva (Gómez 2006 y 2012), muestra que la adscripción cronológica de los inicios del período histórico-arqueológico se había mantenido sin revisar a lo largo de más de cuarenta años, y para algunas líneas de investigación todavía parece continuar dentro de los mismos parámetros.

Aunque en otro lugar se han analizado pausadamente los inicios y fundamentos de ese error metodológico (Gómez e.p.), reiteramos que en los años finales de la década de los sesenta, evidentemente por simple lógica más que por razonamiento científico, se estimó que en el Cabezo de San Pedro los sedimentos incluidos en los Niveles 5 y 6 , al no aparecer en ellos cerámicas a torno fenicias, debían pertenecer a los siglos IX-VIII a.C., o como mucho al $\mathrm{X}$ a.C., toda vez que la presencia fenicia más temprana, todavía en esos años, no se adscri- 


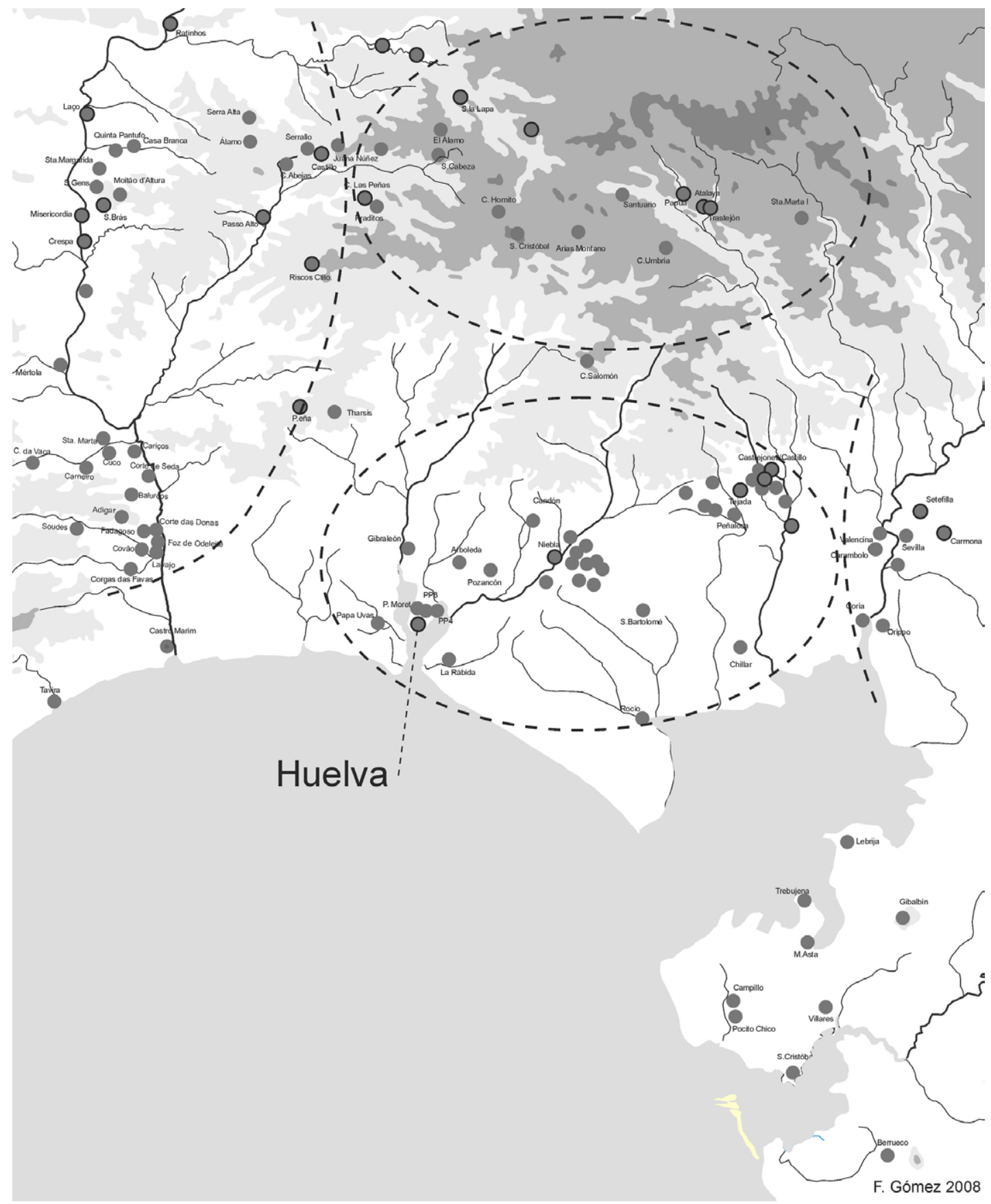

Figura 1.- El Suroeste peninsular entre los II-I Milenios a.C. (Según Gómez 2008).

bía a momentos anteriores al 700 a.C. (Blanco et al. 1969; Blázquez et al. 1970; Gómez y Campos 2008), una línea interpretativa que coincidía con la que también se obtenía para el final de la Prehistoria Reciente a propuesta de H. Schubart en 1971.

A partir de la década de los años sesenta esa horquilla cronológica, entonces estimada hipoté- ticamente para el Bronce Final como único y simple planteamiento posible, se continuó aplicando durante las décadas siguientes a los materiales locales localizados en un amplio número de excavaciones y prospecciones superficiales llevadas a cabo en el Suroeste en general, en las que también aparecieron materiales a torno superpuestos 
o interrelacionados entre sí. Dado que en las décadas más recientes la cronología fenicia, utilizando principalmente el referente de Tiro (Bikai 1978) o de Chipre en general como complemento (Bikai 1987), se fue adelantando prácticamente dos siglos, desde el 700 al 900 a.C., algunos investigadores, tratan de otorgar la misma cronología a la sociedad local del Bronce Final que a los inicios de la presencia fenicia en Occidente, sincronizando ambas. Como posición más extrema, se ha llegado incluso a calificar como del Hierro I a las cerámicas locales encontradas en un estrato presuntamente arqueológico de Huelva que, tal y como se ha publicado, se presume cronológica y culturalmente uniforme (González de Canales et al. 2009). Ello no ha sido óbice para que uno de los autores del presente trabajo lo haya criticado recientemente para explicar las relaciones entre el Suroeste y Cerdeña en el Bronce Final prefenicio (Gómez y Fundoni 2011), o de la evolución del Suroeste en general (Ruiz-Mata y Gómez 2008).

Sin querer entrar en un debate históricamente estéril, que nos retrotraería conceptualmente al estado de la investigación de hace más de medio siglo, inmersa en criterios de periodización interna de la Edad de los Metales basados en la más temprana aparición de un metal concreto, o del paradigma de la colonización desde ópticas hiperdifusionistas, obviando de esta forma procesos sociales, políticos y económicos locales mucho más complejos, cabe hacer una reflexión metodológica. $\mathrm{Si}$ algunas de las cerámicas locales recientemente publicadas pudieran integrarse por su relación con materiales fenicios importados desde Oriente en ese Hierro I occidental, en qué periodo históricoarqueológico deberíamos incluir los mismos tipos cerámicos localizados en la Sierra de Huelva (Gómez 1998; Hurtado 2007; Hurtado et al. 2011), en el conjunto del Bajo Guadiana o del Bajo Guadalquivir, ¿en la Edad del Bronce o en la del Hierro? Todas las cerámicas locales decoradas con motivos bruñidos no son del siglo IX a.C. o posteriores, sino que también hay tipos que deben llevarse a los siglos finales del II Milenio a.C. (Gómez 2008; Hurtado 2007). En realidad no podemos olvidar que el final de la Prehistoria está suficientemente probado en todo el Suroeste antes del siglo IX a.C.

Las novedades que presentamos sintéticamente en este trabajo proceden del registro obtenido en los últimos años en la zona agrícola situada al norte de la Huelva protohistórica, directamente relacionada con la ciudad portuaria. Entendemos necesario avanzar unas primeras conclusiones por su repercusión en el estado del conocimiento del período histórico-arqueológico en cuestión, aunque al menos sólo sirvan para fomentar el debate

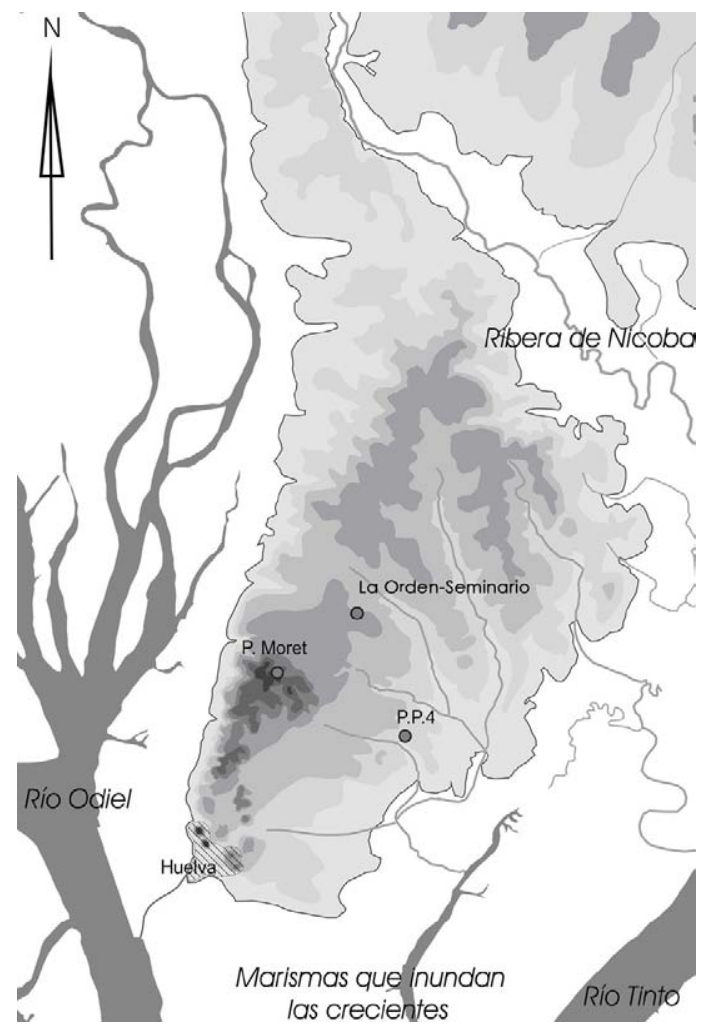

Figura 2.- Situación del Puerto de Huelva y de La Orden-Seminario entre los ríos Tinto y Odiel.

científico, hasta que pueda presentarse la totalidad del registro obtenido dada su magnitud, imposible en un soporte como el que ahora utilizamos.

\section{El yacimiento de La Orden-Seminario}

El yacimiento actualmente delimitado y protegido se denomina administrativamente Sector B-3 "Santa Marta-La Orden" en la declaración de la Zona Arqueológica de Huelva, coincidiendo urbanísticamente con los terrenos incluidos en el Plan Parcial 8 "Seminario" al norte de la Huelva actual (Fig. 2). Ocupa una finca que constituye un rectángulo de unos 700 metros en el eje este-oeste y 500 metros en el eje norte-sur, extendiéndose por una superficie total de más de 230.000 metros cuadrados (Fig. 3). Para el período en cuestión, la zona estudiada corresponde al sureste del rectángulo, donde las curvas de nivel, muy separadas, indican la existencia de una pequeña elevación que alcanza una altura de 39 metros sobre el nivel del mar, delimitada por sendos arroyos estacionales que confluyendo en el Arroyo y Estero del Rincón acabarían desaguando en los esteros mareales del río Tinto (Fig. 2). 

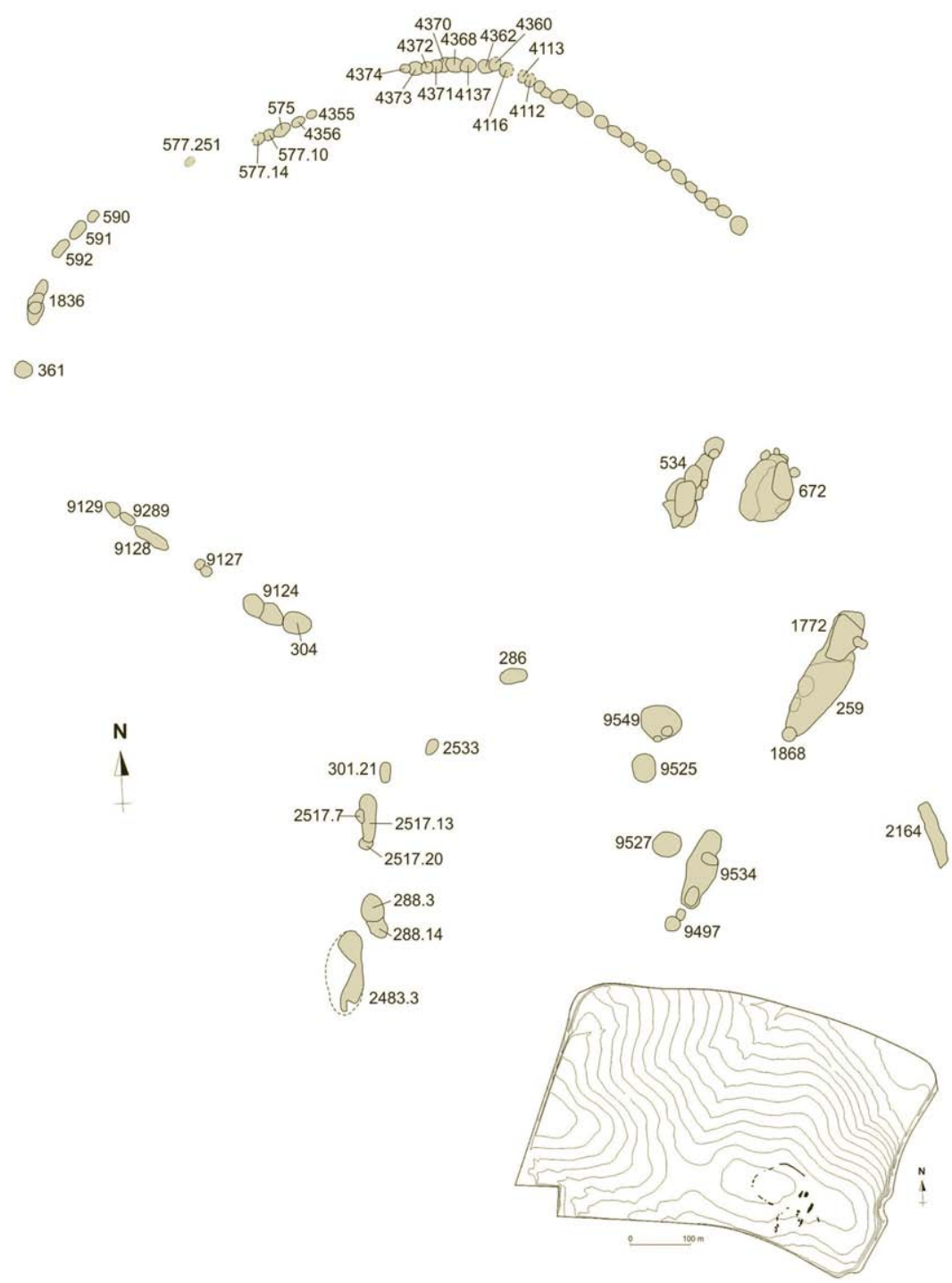

Figura 3.- Planta del espacio ocupado por el asentamiento del Bronce Final de La Orden-Seminario y ubicación dentro del Sector B-3 de la Zona Arqueológica de Huelva.

El sustrato geológico de la zona corresponde a depósitos marinos de la formación geológica Arenas de Huelva correspondiente al Plioceno Inferior-Medio, de tonalidad blanquecina-amarillenta que localmente aparecen sobremontados por restos de una terraza cuaternaria de color rojizo. Puesto que la totalidad de las estructuras son de carácter negativo, y sus rellenos estratigráficos presentan unas matrices de naturaleza arcillosa o limo-arenosa, con unas tonalidades que varían entre el rojo intenso y el pardo, además de basuras y restos orgánicos heterogéneos de génesis antrópica o antropizada, su identificación se facilita una vez retirado el estrato superficial alterado por el arado contemporáneo, mostrándose un complicado palimpsesto de miles de estructuras arqueológicas sujetas a análisis denominadas Punto de Excavación o PEX (Figs. 9 y 10).

Por sus características patrimoniales, la excavación de la superficie total no se ha completado, continuando algunas parcelas en situación preventiva, o bien los trabajos de campo fueron realizados por diferentes empresas arqueológicas, lo cual en determinados aspectos dificulta el acceso a la documentación de su poblamiento (Vera et al. 2010). La base documental que aquí presentamos procede de un conjunto de intervenciones arqueológicas llevadas a cabo en los viales y parcelas de la ur- 


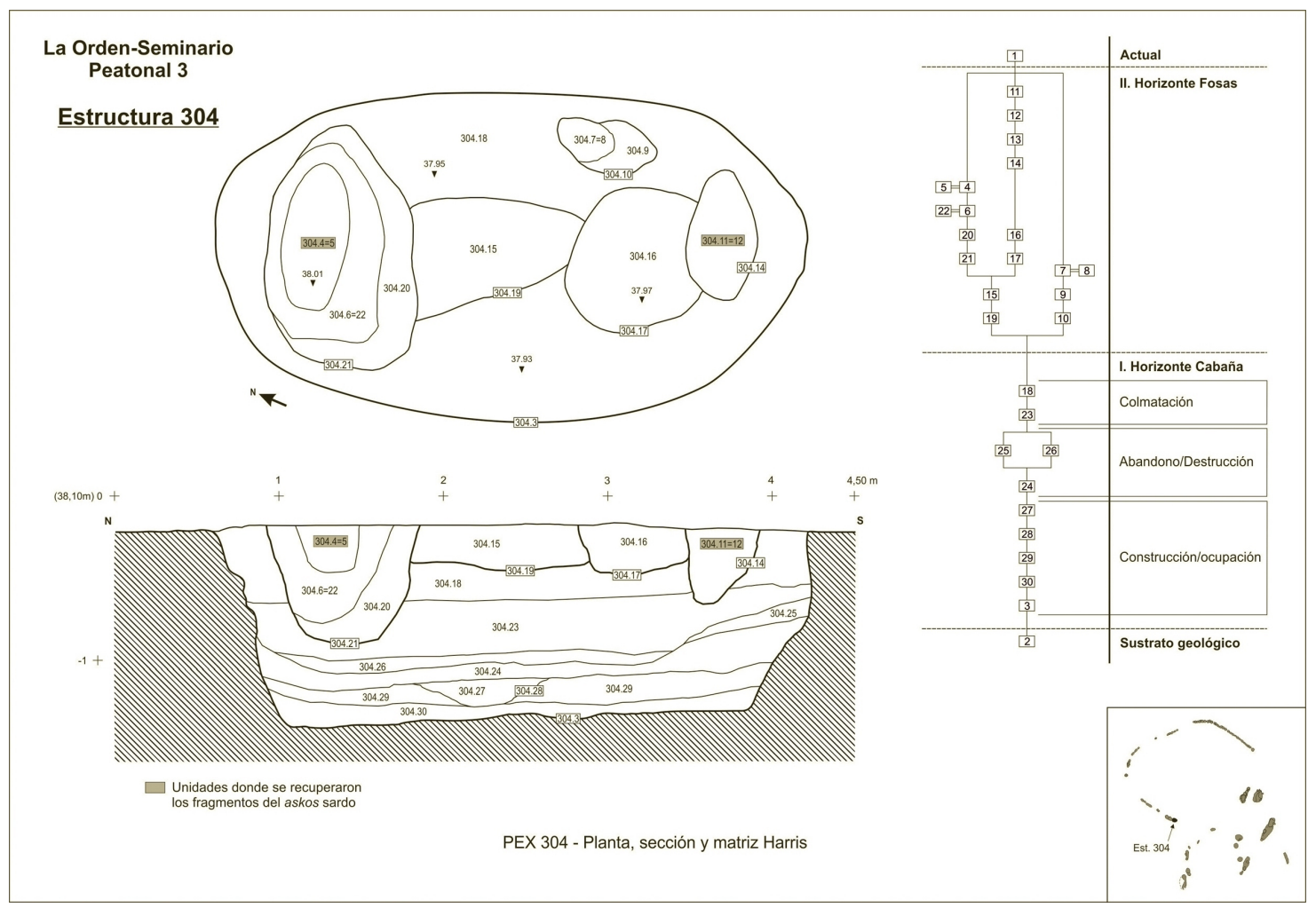

Figura 4.- Estratigrafía de la pithouse PEX 304 con indicación de las UUEE de procedencia del askos sardo.

banización por la empresa Ánfora GIP, con la que la Universidad de Huelva suscribió dos Contratos de Investigación sucesivos de asesoría científica y apoyo técnico en paralelo a las excavaciones.

Uno de los aspectos más novedosos y relevantes es la cantidad y calidad del registro tanto en cuanto a su extensión real como en la superposición de miles de estructuras arqueológicas definidas a través de su excavación sistemática estratigráfica, sin olvidar que la mayor parte de la superficie está todavía por excavar. Ello indica, por un lado, que la población local fue construyendo cabañas y otras estructuras negativas de habitación o almacenamiento que se sucederían las unas a las otras en el tiempo y en el espacio y, por otro lado, que también el propio espacio fue cubierto de explotaciones agrícolas sucesivas, algunas de las cuales, las más profundas y dedicadas a arboricultura, dejaron su impronta reflejada en el subsuelo (González et al. 2008; Fig. 9 y 9a-d; Vera y Echevarría 2013), para conformar un entramado de huellas de cultivo superpuestas cuya excavación y posterior estudio posibilita la reconstrucción del proceso de habitación y uso agropecuario en una horquilla cronológica que se extiende desde la prehistoria hasta la actualidad (González et al. 2008; Vera et al. 2010).
En contraposición a los datos que ahora avanzamos, en el Suroeste peninsular y en relación con el conocimiento del desarrollo de la última fase de la Prehistoria Reciente, en general hasta ahora solo se contaba con el resultado de estratigrafías realizadas en la mayor parte de los casos en asentamientos superpuestos de complicadas estratigrafías, donde los niveles más antiguos fueron arrasados o modificados en su día por la población posterior. Precisamente en Huelva los datos más relevantes proceden de dos recogidas selectivas de materiales en actividades no estrictamente arqueológicas separadas en el tiempo casi por cuatro décadas: A finales de los años sesenta en el propio Cabezo de San Pedro (Blázquez et al. 1970), y en los inicios del nuevo milenio los materiales recogidos en limos extraídos de las antiguas marismas continentalizadas de Huelva (González de Canales et al. 2004).

También se ha contado con la excavación de cabañas en poblados simples, cuyo registro fue interpretado a partir de planteamientos metodológicos hoy superados (Gómez et al. 2009). Tal vez esas circunstancias puedan dar una idea del conocimiento alcanzado en general en esos momentos, tal como se ha comentado más arriba. 


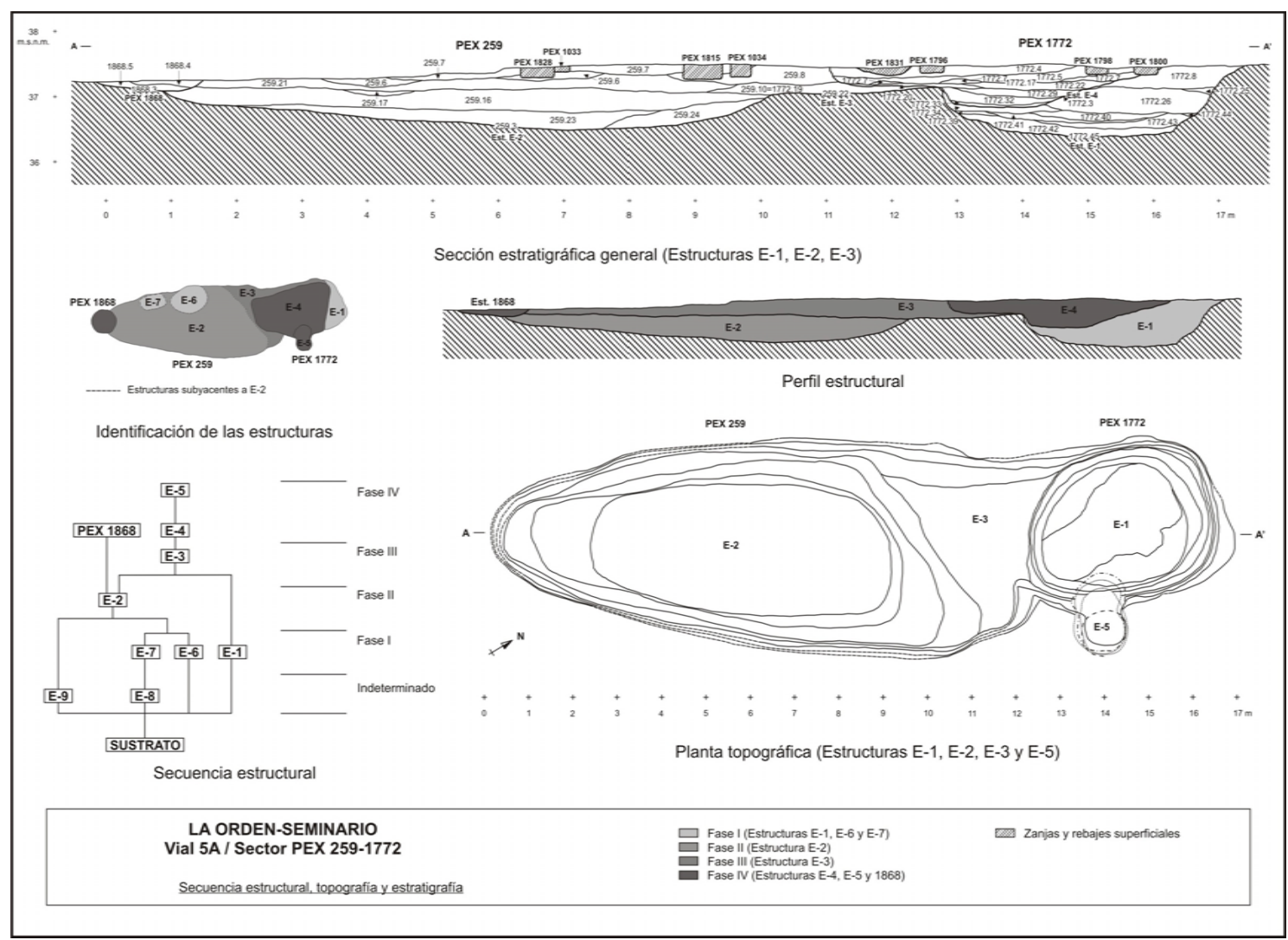

Figura 5.- Estratigrafía de la superposición de las diferentes estructuras y fases del PEX 259-1772.

De esta manera, el seguimiento material de un segmento importante de la población de la Edad del Bronce en el entorno del puerto de Huelva a través de un registro arqueológico normalizado, moderno y exhaustivo, en un espacio determinado a lo largo del desarrollo ocupacional comprendido entre los siglos finales del II Milenio a.C. y los inicios del Período Turdetano permite confirmar, a partir de ese cuerpo de datos, la posible vigencia o el rechazo de las aseveraciones e hipótesis largamente vigentes en el Suroeste peninsular que hemos comentado anteriormente, en especial las relacionadas con la cronología relativa al final de la Edad del Bronce desde su comienzo y su evolución en el tiempo hasta entroncarse con el Período Orientalizante de los siglos VIII-VI a.C.

Para comprender el futuro alcance de los trabajos realizados y su posible repercusión en la investigación arqueológica de la Edad del Bronce en el Suroeste peninsular, avanzaremos que con las evidencias excavadas ahora se constata en la península de Huelva la existencia de población de la Edad del Bronce durante gran parte del II Milenio a.C. especialmente durante el periodo histórico- arqueológico del Bronce Final, situado ahora a grandes rasgos entre los últimos siglos de ese II Milenio a.C. y principios del siguiente (Gómez 2006), con continuidad durante el periodo orientalizante (López y Vera e.p.). Una muestra similar ya se había excavado en el Cabezo de San Pedro hace cuarenta años (Blázquez et al. 1970; Gómez y Campos 2008), la cual no había sido suficientemente explicada en su día en principio por una lógica falta de datos disponibles o, como ya hemos explicado, por el sistema aleatorio en que se produjo la recogida de materiales (Gómez y Campos 2008), ya que la investigación de la Protohistoria peninsular todavía se encontraba en ciernes, y tal como se planteó la publicación entonces parecía suficiente.

En lo que se refiere a las formas de hábitat, contamos ahora por primera vez en el conjunto del Suroeste con un registro normalizado y exhaustivo de la sucesión en el tiempo y en el espacio de las formas de habitación en un entorno económico y productivo específico, sin duda vinculado al espacio portuario de la Huelva protohistórica, que permitirá plantear analogías con paralelos conocidos 
en otras áreas mediterráneas en lo que se refiere al concepto de ciudad o asentamiento principal y su chora o ruedo agrícola y ganadero, al situarse este espacio excavado a escasa distancia del puerto, en una zona llana y bien regada comprendida entre los mencionados ríos, donde solo existían arroyos estacionales que nunca pudieron ser un impedimento para el flujo de personas y mercancías, así como para su aprovechamiento en explotaciones agropecuarias (Fig. 2). De la misma manera, por su cercanía a esteros ahora continentalizados en la marisma del río Tinto como el de El Rincón, en ese período histórico, la sociedad local obtenía beneficios complementarios de la pesca y de la recolección de moluscos como en períodos anteriores, de los que aparece una buena representación en los fondos de cabaña y basureros sincrónicos excavados, los cuales se han conservado para su posterior estudio.

Las estructuras detectadas y excavadas hasta ahora permiten constatar claros cambios en el tamaño y en la disposición de las cabañas y de otras estructuras negativas, un hecho que tal vez responde a diferentes funciones, renovaciones del hábitat separadas por diversos pavimentos $\mathrm{y}$, en su caso, hogares, hornos y áreas de consumo, almacenamiento o producción, cuyos restos conservados también podrán servir a partir de su estudio para estimar la dieta y otras formas de vida de la gente que las habitó, así como determinar su cronología calendárica mediante análisis de $\mathrm{C} 14$. Parece interesante destacar aquí, en contra de lo conocido en el entorno del puerto en Huelva y en otros asentamientos de la Tierra Llana (Gómez 2006), que prácticamente no se han recogido escorias de plata en las áreas excavadas, tal vez por la específica vinculación agropecuaria de las estructuras de hábitat, o quizás porque la producción de plata solo se hizo en la zona portuaria.

Un análisis preliminar de los materiales cerámicos relacionados con esas estructuras permite comprobar la presencia de formas que pueden relacionarse con los Horizontes Formativo y Clásico del Bronce Final propuesto por uno de nosotros (Gómez 1998; 2008), estando incluidos en el último de ellos los tipos locales más evolucionados que se utilizaban en el momento de la recepción de las primeras importaciones orientales en Huelva. El desarrollo posterior de estas formas y su evolución simultánea junto a las producciones torneadas que caracterizan al Período Orientalizante y a los inicios del Turdetano, un espacio temporal que en otro lugar ha sido denominado Horizonte Residual del Bronce Final, y que se sitúa ya a partir de mediados del siglo VIII a.C. (Gómez 2008), puede detectarse en cabañas Orientalizantes en las
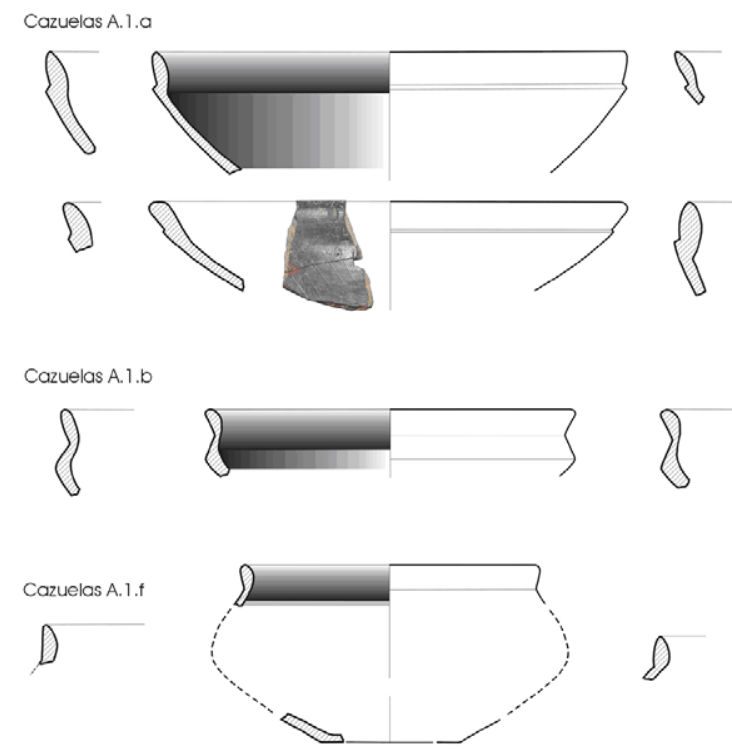

Copas B.1f/b.
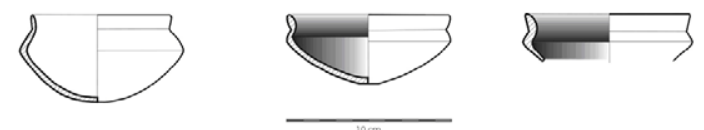

Figura 6.- Tipología del Horizonte Formativo en La Orden-Seminario.

que predominan las formas cerámicas a torno de tradición fenicia occidental de mediados del siglo VII e inicios del VI a.C. (López y Vera e.p.) y en otras algo más recientes ya del pleno siglo VI con importaciones griegas para finalizar en una fase avanzada del siglo V con la aparición de copas Cástulo (Vera y Echevarría 2013), todas ellas bien contextualizadas a partir de la tipología anfórica y otras producciones.

Con este hilo conductor claramente se documenta la superposición en el tiempo de los diferentes horizontes arqueológicos del Bronce Final y la Protohistoria ahora definidos en Huelva, no solo a partir de estructuras de hábitat sino también, como novedad, a través de sistemas de cultivo normalizados y estructurados espacialmente que cortan o son cortados por cabañas. Este hecho permite establecer la antero-posterioridad de las diferentes estructuras relacionadas en estratigrafía horizontal (Vera y Echevarría 2013), difícilmente observables, como ya se ha dicho anteriormente, en un yacimiento superpuesto como Huelva, o en cualquier otro, donde las fases posteriores bien han destruido las evidencias previas o bien éstas se encuentran incluidas en depósitos posdeposicionales que abarcan períodos demasiado extensos (Gómez et al. 2007). 
Copa B2b

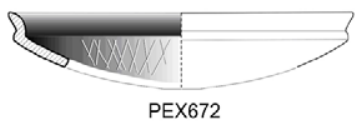

Horizonte Clásico (1000-750 a.C.)

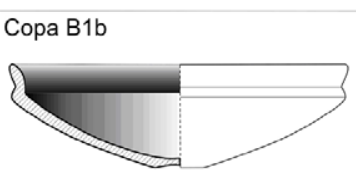

PEX259

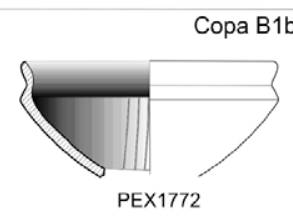

Transición (ca. 1000 a.C)

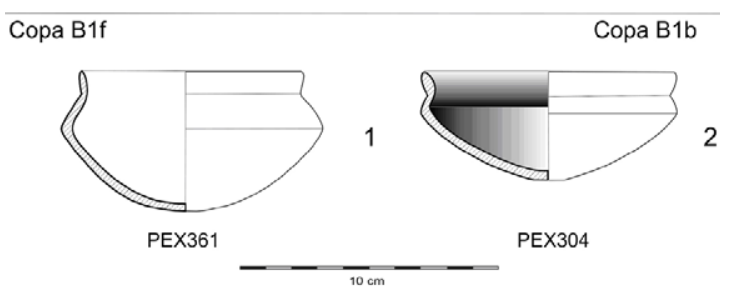

Horizonte Formativo (1250-1000 a.C.)

Figura 7.- Síntesis evolutiva de la forma Copa en La Orden-Seminario (cronologías de las fases según Gómez 2008).

Conocido el ajuar cerámico que aporta la excavación sistemática de las fosas y zanjas de cultivo, con la cronología relativa que aportan las superposiciones documentadas entre ellas mismas y con los fondos de cabaña mejor fechados que resultan coherentes a lo largo de más de medio milenio, las huellas de cultivo son un importante referente para establecer la evolución en el tiempo de diferentes sistemas agrícolas en este espacio específico (Vera y Echevarría 2013), la chora de la ciudad protohistórica de Huelva durante el final de la Edad del Bronce y a lo largo de la del Hierro.

De lo anterior se desprende que la excavación sistemática de las unidades estratigráficas ha permitido establecer tanto el tiempo como el espacio de los ítems arqueológicos documentados, lo que va en contra de la consideración de las estructuras negativas que hasta ahora se han denominado en la historiografía protohistórica del Suroeste 'fondos de cabaña', realmente pithouses si utilizamos otra más específica, como meros contenedores de artefactos. De esa manera, el hecho de que falte la huella de postes o que los que podemos considerar hábitats estén excavados en el subsuelo terciario hasta cierta profundidad, las aleja de las cabañas de elementos vegetales que todavía pueden obser- varse en pie en Doñana y que hasta ahora sirvieron de paralelo etnográfico (Gómez et al. 2009).

\section{Evolución del asentamiento}

La evolución en el tiempo de cada una de las estructuras o Puntos de Excavación (PEX) excavados, ya sean fondos de cabaña, otras estructuras de hábitat o huellas de cultivo, se ha establecido a partir del análisis estratigráfico de las relaciones de antero-posterioridad manifestadas principalmente por relaciones de corte entre elementos interfaciales debido a la repetición en un mismo espacio de unas técnicas de construcción negativas específicas, así como de otras relaciones de superposición vertical en los rellenos de las propias estructuras. La sucesión temporal en horizontal del poblado se va completando paulatinamente a partir de la elaboración de tipologías analíticas definitorias de los útiles documentados, y de la posición relativa en su contexto de los objetos de cultura material siguiendo trabajos recientes (Gómez 2008), que son una revisión o puesta en día de las establecidas por el Dr. Ruiz Mata (1979; 1995).

Si hasta hace poco la valoración histórico-cronológica de las cerámicas locales se establecía a partir de tipologías publicadas hace treinta años, precisamente el estudio estratigráfico de las estructuras de La Orden-Seminario permite ahora observar cambios que han dado pie para establecer una evolución morfológica más precisa que antes no era posible, puesto que las excavaciones realizadas en el hábitat superpuesto de Huelva y la primitiva metodología utilizada en otros asentamientos simples de cabañas tan solo mostraban unos aspectos generales, que ahora van siendo completados debido a la naturaleza de estos hábitats, puesto que únicamente pudieron ser utilizados durante un escaso margen de tiempo debido a su morfología de tipo pithouse, y por ello las diferentes superposiciones registradas en una misma estructura son la vía a partir de la cual es posible establecer pautas diferenciales y similitudes relativas o específicas para su comparación tipológica.

Es decir, a partir de la posición estratigráfica del conjunto de los vasos cerámicos y otros artefactos, en mayor o menor grado de fragmentación dependiendo de la génesis de los depósitos (ya sean de origen antrópico directo y "primario" - -suelos pisados y también barridos para su aseo, contextos de uso- mejor o peor preservados, o "secundarios" aportaciones de desechos y descartes de acciones y actividades antrópicas que discurrían en las zonas periféricas de las estructuras, asociadas funcionalmente o no a las mismas-, o bien depósitos debi- 


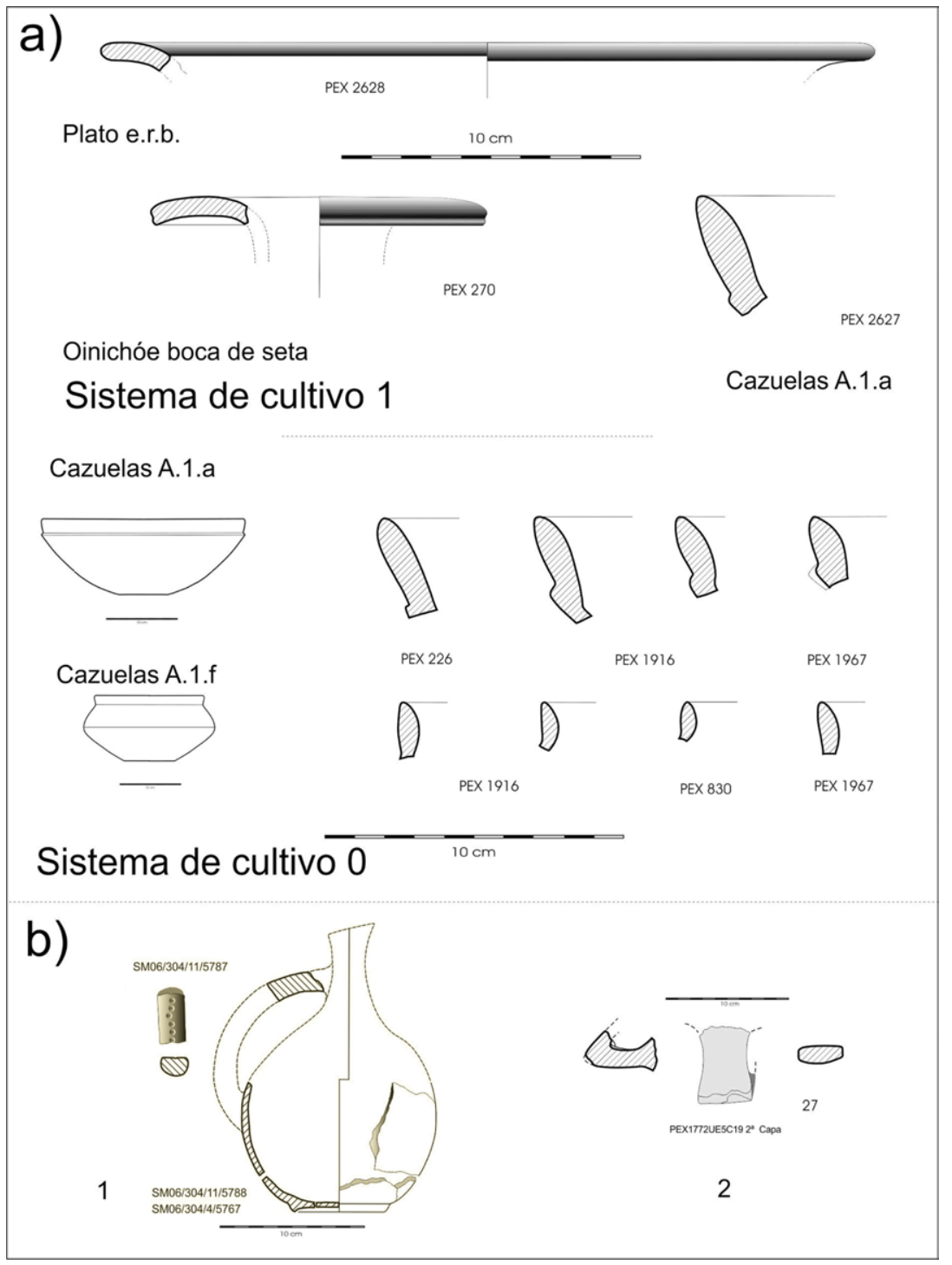

Figura 8.- a) Materiales relacionados con diferentes sistemas de cultivo. b) Importaciones sardas.

dos a procesos de colmatación siguiendo leyes físicas universales con mayor o menor intervención humana), es posible contrastar sutiles cambios en las técnicas de fabricación y en su tratamiento final, así como en el acabado formal de las piezas y la aplicación, en su caso, de sistemas decorativos específicos, para apreciar su evolución en el tiempo. Con carácter general es necesario valorar en cada caso la significancia de las novedades y perduraciones relacionadas con diferentes momentos de su fabricación, uso, deterioro y/o amortización post-rotura, que los llevaría a formar parte de la basura que se genera y desecha en cada momento, para finalmente formar parte de los sedimentos que colmatan de forma antrópica, natural, o com- binada las cuencas de deposición creadas por las pithouses amortizadas o en proceso de abandono.

Partiendo de la planimetría de distribución de las estructuras del Bronce Final en La OrdenSeminario, (Fig. 3) es posible estimar formas de ocupación sucesiva del espacio para su habitación y uso agropecuario (González et al. 2008), siendo posible establecer relaciones entre determinadas estructuras de hábitat y campos de cultivo (Vera y Echevarría 2013).

Algunas de las estructuras que por el momento parecen ser las más antiguas según una primera valoración de las producciones cerámicas recuperadas, se disponen formando una serie o alineación coherente de pequeñas fosas de planta sensible- 


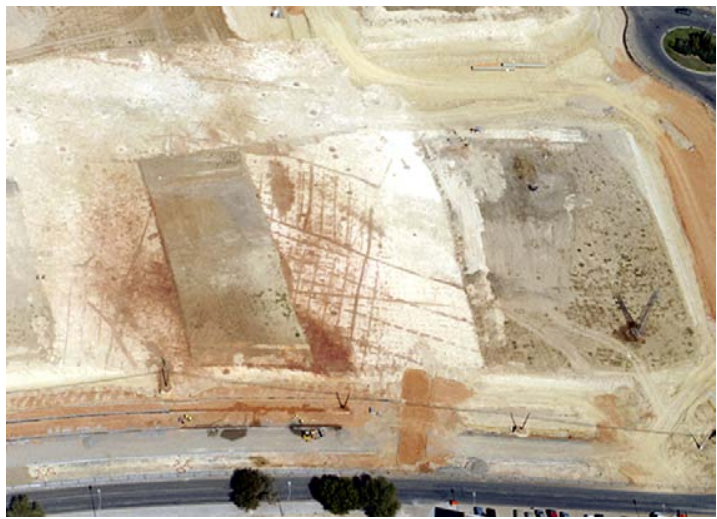

Figura 9.- Fotografía aérea del extremo SE de La OrdenSeminario.

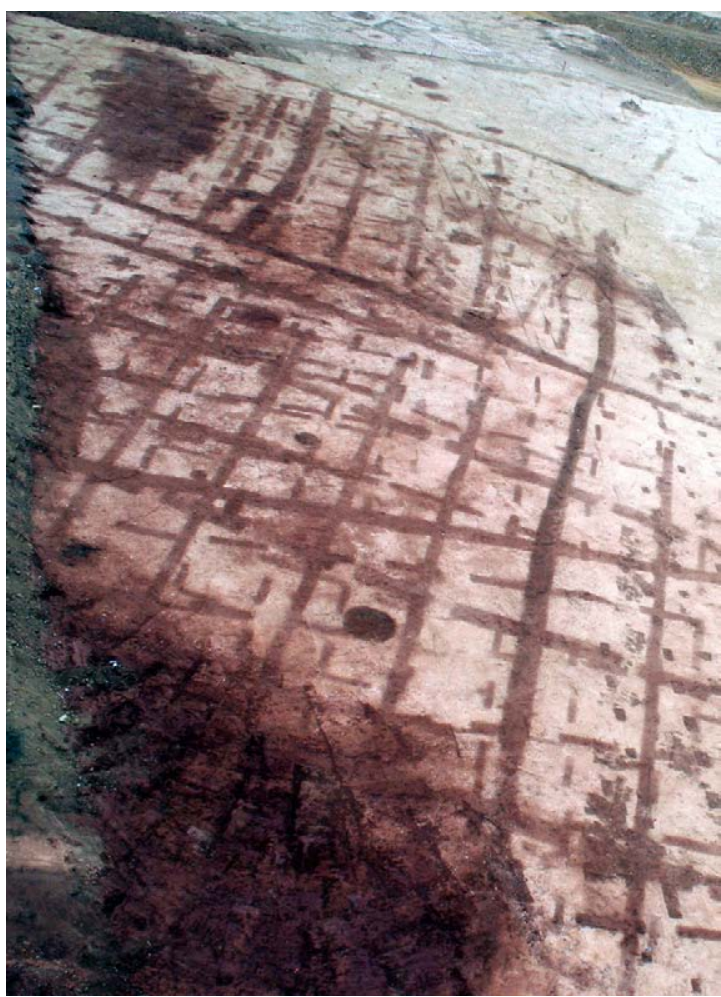

Figura 10.- Estructuras arqueológicas situadas bajo la superficie agrícola al inicio de los trabajos en el Vial 5A.

mente circular o ligeramente oblonga a partir de relaciones de yuxtaposición y superposición parcial reiterativas. En planta, su recorrido describe una especie de $\mathrm{U}$ ancha, de lados rectilíneos y base de delineación curva u oval con la convexidad hacia el noroeste, abierta por tanto hacia el sureste, que ocupa el sector noroccidental del poblado con un diámetro aproximado de alrededor de $60 \mathrm{~m}$. En esta serie se intercalan algunas estructuras de hábi- tat de mayor tamaño como los PEX 304 y 361 . Al sureste del óvalo irregular así definido, se localiza el grueso de las estructuras de la Edad del Bronce, si bien existen fondos de cabaña en posición más septentrional o meridional. Funcionalmente cabe relacionar este recinto como la materialización de un tipo de cercado muy común en diversas sociedades agrícolas y ganaderas tradicionales conocidas en diversas áreas mundiales hasta la actualidad, destinado a aislar una zona donde salvaguardar el ganado, concentrar los excedentes agrícolas, el utillaje de trabajo y los enseres domésticos. La delimitación física de estos espacios suele realizarse a partir de un seto de especies vegetales arbustivas de carácter espinoso, o bien mediante la yuxtaposición de estructuras, a veces graneros y viviendas, cuyas traseras se orientan hacia el exterior del recinto mientras que sus accesos lo hacen hacia el interior. La funcionalidad de las estructuras de menor tamaño, que no llegan a superar los $50 \mathrm{~cm}$ de profundidad, pudo pues variar según los casos y el momento concreto -recordemos que establecen relaciones de superposición- desde fosas de siembra correspondientes a tramos del cerco constituidos de setos vegetales, hasta pequeñas estructuras de almacenamiento, ocasionalmente reutilizadas como fosas de vertido en el momento de su amortización, pero también dedicadas a otras actividades productivas como es el caso del horno PEX 1836. La temporalidad dentro del Bronce final deberá ser establecida a partir del estudio comparativo de los ajuares cerámicos contenidos en aquellas estructuras que mantienen relaciones de corte. Con posterioridad, a una parte de estas estructuras se les superpondrá un fondo de cabaña construido ya durante el Periodo Orientalizante (López y Vera e.p.).

En relación con determinadas estructuras que forman parte de la alineación, podemos avanzar algún comentario para definir la morfología de los PEX 361 y PEX 1836. Mientras que el primero es una estructura de tendencia circular, cuyos depósitos superiores están originados por vertidos intencionales entre los que se documentan importaciones sardas, el segundo es también una estructura más compleja conformada por tres fosas superpuestas de las cuales al menos una tuvo la función de horno/ combustión. La unidad estratigráfica más reciente, que rellena la fosa más moderna de esta última estructura, muestra ya algún elemento cerámico que puede integrarse en el Horizonte Clásico del Bronce Final, confirmando así su relación con una actividad posterior que perpetúa el uso de este espacio.

Incluida en la planta del cercado, como elemento más representativo por sus características estratigráficas y materiales arqueológicos obtenidos, 


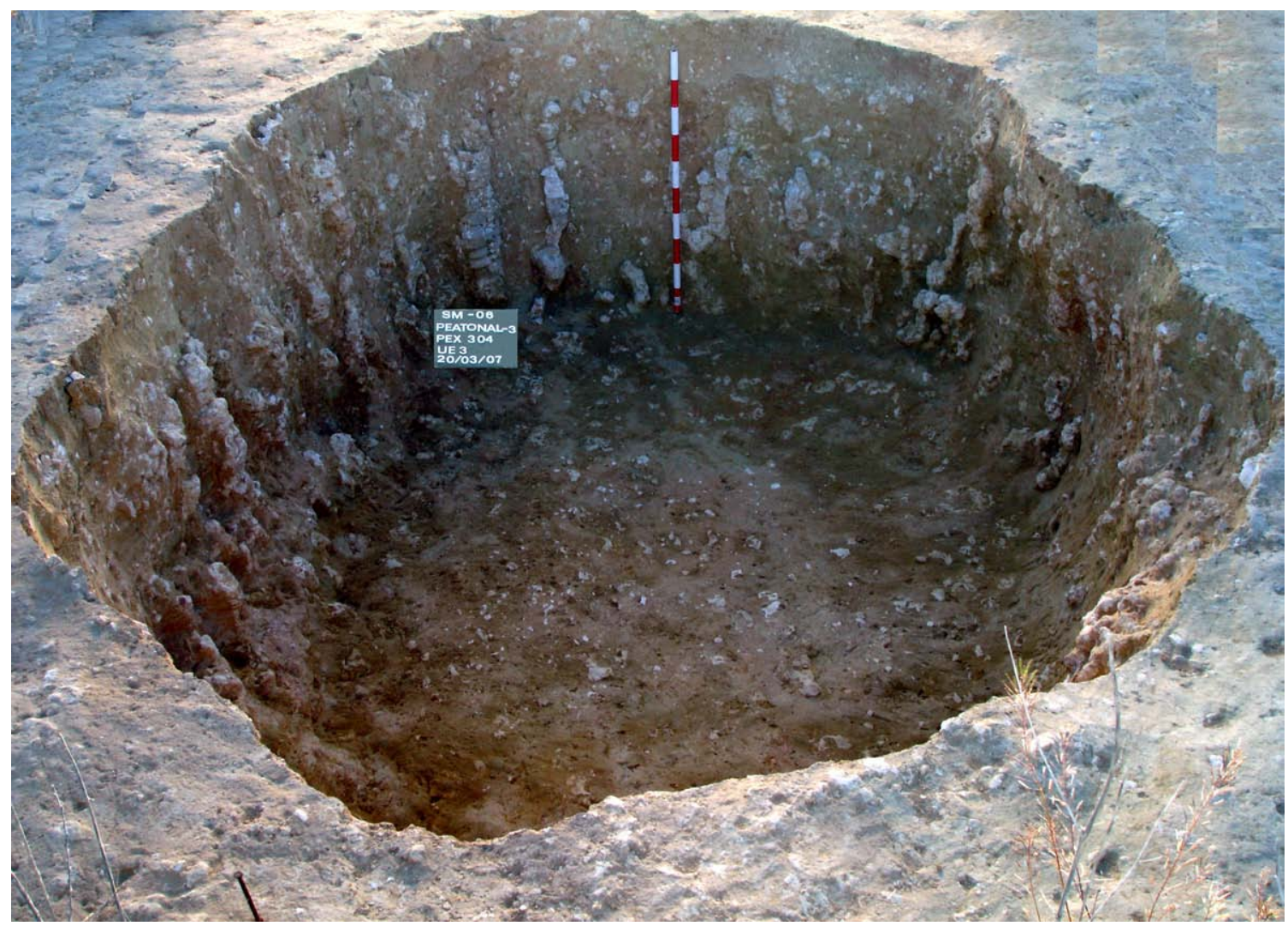

Figura 11.- Fase final de la pithouse PEX 304.

debemos estimar la estructura denominada PEX 304 (Figs. 4 y 11). Se trata de una estructura cuyas dimensiones oscilan entre 3'75 metros de eje esteoeste y 2'10 metros en sentido norte-sur y 1'10 metros de profundidad máxima. Las unidades estratigráficas más profundas conforman los restos de una ocupación que podría integrarse por criterios tipológicos del material asociado en una fase tardía del Horizonte Formativo del Bronce Final de Huelva (Gómez 2008).

Durante el proceso de abandono de la estructura como cabaña o pithouse, se depositaron un conjunto de unidades estratigráficas superpuestas aparentemente por combinación de acciones antrópicas intencionadas con procesos naturales que llegaron a colmatar totalmente - o casi- su volumen. Con posterioridad, el resto de unidades estratigráficas más recientes que se superponen son pequeñas fosas u hoyos excavados dentro del ámbito del relleno de la propia estructura, que en consecuencia no deben estar directamente relacionados con la ocupación primigenia. En estas unidades más recientes aparecieron diferentes fragmentos de un askos nurágico (Fig. 8b, 1), un pequeño contenedor de procedencia sarda que en la isla centromediterrá- nea se fecha en la Edad del Bronce (Fundoni 2009: Lám. III, 2).

Con posterioridad a estas estructuras encuadrables tipológicamente en la última fase " $C$ " del Horizonte Formativo del Bronce Final, establecido hipotéticamente en el último siglo del II Milenio a.C. al faltar en las estructuras excavadas las formas cerámicas que indicarían una mayor antigüedad (Gómez 2008: Fig. 3), las primeras estructuras situadas ahora fuera del mencionado espacio cercado están representadas conjuntamente por los PEX 1772 y PEX 259, donde las relaciones estratigráficas muestran diversas fases de ocupación y/o superposición de diferentes cabañas o distintos usos.

La construcción del primer hábitat de esta fase se documenta a partir de la estructura aislada 1772/ E1, que está conformada en su base por unidades estratigráficas de ocupación cuyos materiales identificados corresponden a las formas de Cazuela A1a y Copa B1b y B1f(Figs. 6-7). Esta primera cabaña (I), en un momento preciso, bien se abandonará o bien será destruida completamente, tal vez para construir la siguiente que se ubicará junto a la ya amortizada. El registro post-ocupacional 


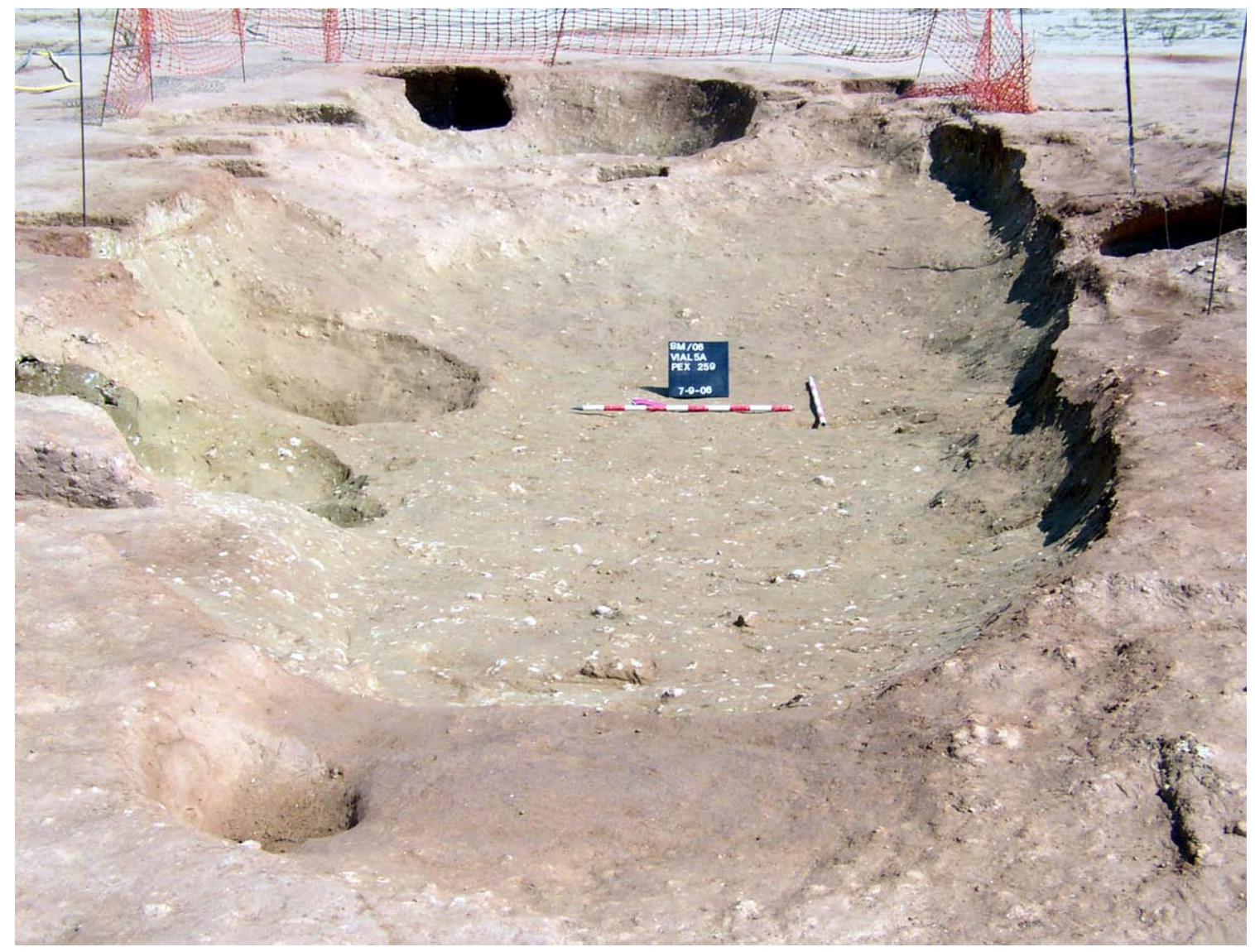

Figura 12.- Fase final de la excavación de los PEX 259-1772.

estaría conformado por depósitos de colmatación predominantemente natural relacionados con el proceso de abandono. A la mencionada estructura 1772/E1 se asocian otras dos estructuras, 259/E-6 y $259 / \mathrm{E}-7$, que hemos interpretado como fosas de posible almacenamiento finalmente amortizadas mediante vertidos intencionales.

Una segunda fase (II) está representada por la Estructura 259/E-2, con depósitos de colmatación uniformes generados a partir de sedimentación natural, todos ellos posteriores al uso de la misma como vivienda o hábitat en general. La siguiente fase constructiva (III) se define como una ampliación de la Estructura 259/E-2 formada por un depósito de ocupación, subyacente a un contexto sedimentario que habría que relacionar con el episodio posterior de abandono/destrucción de dicha área. Finalmente se registran los rellenos comunes de colmatación final a las sedimentaciones indicadas de las estructuras E-2 y de su área de ampliación, E-3.

Una última fase de ocupación (IV) y su posterior abandono está representada por la Estructura
1772/E-4, con un primer episodio deposicional, tal vez intencionado, correspondiente a la secuencia de relleno postocupacional de la estructura y sucesivos depósitos de colmatación, ya sean de génesis natural, antropizada o antrópica. La fase estrictamente de habitación de la cabaña está representada por un segundo episodio deposicional consistente en sucesivos suelos de ocupación que termina con una fase de basurero.

Tanto los materiales del nivel de base como los documentados en los diferentes rellenos se corresponden tanto con formas que pueden incluirse en el Horizonte Formativo como en el posterior Horizonte Clásico del Bronce Final de Huelva (Figs. 5 y 6), circunstancia que nos lleva a estimar que las diferentes cabañas que aquí se superpusieron fueron habitadas hasta que finalmente quedaron amortizadas en una fase de transición que estimamos se extendería entre ambos Horizontes, y que desde un punto de vista crono-estratigráfico debemos situar en momentos cercanos a finales del siglo X y la mayor parte del siglo IX cal. a.C. De las importaciones documentadas entre los materia- 
les excavados, quisiéramos resaltar la existencia de un asa a gomito rovescio recuperada en la E-4 (Fig. 8b, 2) que pudo corresponder bien a un vaso contenedor de los denominados vasi a colo, o tal vez a una ciotola, ambos vasos de tipología y fabricación sarda que se incluyen entre las cerámicas típicas de la sociedad nurágica que caracteriza a la ocupación de fines de la Edad del Bronce en la isla de Cerdeña.

La estructura PEX 672, pendiente de un estudio estadístico más exhaustivo y la estimación cronológica a partir de análisis de C14, estuvo formada por varias cabañas superpuestas ocupadas probablemente durante los inicios del denominado por uno de los firmantes Horizonte Clásico del Bronce Final de Huelva, quizás antiguo dentro de esa fase (A-B), pues en los sedimentos excavados aparecen fragmentos de cazuelas del tipo A1a y A1b y otras algo más evolucionadas, así como copas B2b con decoración bruñida sobre la superficie alisada interior (Fig. 7), que serán las formas típicas de ese Horizonte Clásico (Gómez 2008). En cualquier caso, las cazuelas del tipo A1a presentan ya la carena exterior mucho más estrecha que las del Horizonte Formativo anterior, y las superficies bien han perdido calidad por pisado y/o degradación natural, o bien se trataron con una técnica poco hábil que no consiguió la calidad del bruñido de la fase formativa anterior, lo cual tal vez indica un cambio en los hábitos o en la tecnología previos. A pesar de que las carenas sean algo más estrechas que las documentadas en las cabañas anteriores, pensamos no deben adscribirse a la fase más reciente del Horizonte Clásico, ya que las Cazuelas A2a de ese Horizonte se definen por presentar el galbo interior alisado simple, sin bruñir, sobre el que pueden o no llevar decoración bruñida.

Aunque las primeras cerámicas fenicias y alguna sarda (Fundoni 2009: Lám. III, 1) de cronología más tardía que las mencionadas anteriormente (PEX 1772 y niveles superiores del 304) han aparecido estratificadas en otras estructuras (PEX 2533 y 288) el registro de estas últimas, todavía en estudio, podría representar las formas finales del Horizonte Clásico de Huelva (Gómez 2008), cuya descripción exhaustiva dejamos para otro momento.

\section{Síntesis y conclusiones}

La relevancia de la base empírica que proporciona el estudio sistemático de las actuaciones patrimoniales realizadas en La Orden-Seminario durante los años 2006-2008, aunque todavía no se haya completado la excavación de las 23 hectáreas programadas ni el análisis pormenorizado del regis- tro arqueológico hasta ahora obtenido, es el único argumento que nos estimula a presentar aquí una rápida síntesis del período histórico-arqueológico en cuestión, tal como se había presupuesto debía existir en el entorno del Puerto de Huelva (Gómez 2006; 2009).

De la misma forma que ya se han publicado avances relativos al yacimiento en general (González et al. 2008), al estudio específico de los depósitos de ídolos cilíndricos y su contexto espaciotemporal del III Milenio a.C. (Vera et al. 2010), de las parcelas dedicadas al cultivo de la vid (Vera y Echevarría 2013), y se encuentran en prensa estudios relativos a la necrópolis de la Edad del Bronce (Martínez y Vera e.p.) y de una cabaña del Período Orientalizante (López y Vera e.p.), a medida que se avance en el estudio de los materiales del período se irán contrastando algunas de las hipótesis que ahora avanzamos o bien, lógicamente, se señalará cualquier cambio o matización que creamos deba hacerse a estas primeras apreciaciones.

De acuerdo con las estructuras de hábitat y uso agrícola hasta ahora estudiadas, alguna solo parcialmente, las evidencias más antiguas del conjunto podrían corresponder a algunas de las fosas y fondos de la alineación curva cuyo trazado inicial puede remontarse por criterios tipológicos hasta finales del II Milenio a.C., en los momentos más tardíos del denominado Horizonte Formativo del Bronce Final (Fig. 3).

Los materiales cerámicos estudiados preliminarmente indicarían la continuidad de la ocupación en un período de transición, más o menos duradero, al mantenerse en los fondos de las nuevas pithouses habitadas (PEX 259 y PEX 1772) tipos cerámicos del Horizonte anterior junto con otros que solo se generalizarán a lo largo del siguiente Horizonte Clásico (Figs. 6 y 7), una tercera ocupación que aparecería representada en cabañas como la 672 .

De acuerdo pues con la explicación de páginas anteriores, a partir del cambio de milenios, en la transición entre los Horizontes Formativo y Clásico, la ocupación de La Orden-Seminario puede relacionarse con importantes cambios estructurales que estarían produciéndose en el Mediterráneo en general y en el Suroeste en particular (Gómez 2013).

No en vano, una nueva forma de interrelación estará llegando a su cenit entre los principales puntos de atracción que interrelacionaron al menos a Chipre, Creta y Cerdeña en esos momentos, tal vez por la vinculación de las tres islas con las formas de comercio heredadas tras la caída de las sociedades orientales de la Edad del Bronce (Lo Schiavo 2009a: 404), fundamentalmente el comer- 
cio del cobre y del estaño para producir bronce que precedería a la Edad del Hierro. Esa interrelación, todavía difícil de explicar pero basada en el hallazgo de formas compartidas, tales como cerámicas nurágicas del Bronce Final que por el este llegarán hasta Commos en Creta (Shaw 1998), o por los bronces atlánticos que comparten Chipre o Cerdeña (Lo Schiavo 2009b: 406-407), los cuales son sin duda un punto de partida de indudable valor para enriquecer la explicación del proceso histórico en el Mediterráneo y su relación con el Suroeste atlántico a lo largo de los siglos XI-X a.C., ese momento oscuro, posterior a la crisis oriental del 1200 a.C., que precedió la llamada Colonización Fenicia de Occidente (Gómez 2013). Las cerámicas nurágicas que integran el registro arqueológico del Bronce Final en La Orden-Seminario que hemos mencionado más arriba, confirman como se esperaba esos contactos de la isla mediterránea con el puerto de Huelva y su hinterland (Gómez y Fundoni 2011), en momentos tan tempranos.

En definitiva, la ocupación del Bronce Final que hemos documentado en la zona del interfluvio Tinto-Odiel, en el ruedo agrícola de la ciudad protohistórica, puede traer nueva luz a la explicación histórica del puerto de Huelva. Se trata de un conjunto de cabañas del Bronce final ubicado en la inmediata campiña fértil dedicado a la explotación agropecuaria del territorio que a partir del cambio del II al I Milenio a.C. comenzará a practicar cultivos arborícolas especializados, indicativos del aumento en la complejidad de la sociedad occidental de estos momentos.
Un cambio en la obtención de recursos parece estar ya en marcha en el conjunto del sitio arqueológico de Huelva. El primer sistema de liños para el cultivo de la vid (Sistema 0) puede relacionarse con las cabañas del período de transición entre los dos primeros Horizontes del Bronce Final (Vera y Echevarría 2013), entre fines del s. X y el s. IX a.C. A partir de este momento se sucederán otros sistemas agrícolas de mayor extensión (Sistema 1), que documentan el abandono de formas de explotación de matiz arcaica y el inicio de otras más novedosas relacionadas con nuevas necesidades que debieron aparecer en esos momentos en el puerto. La evolución del registro arqueológico de los liños para el cultivo de la vid es consecuente con los periodos históricos que reconocemos (Fig. 8).

De acuerdo con el registro arqueológico excavado, en La Orden-Seminario se asiste al final de la Prehistoria reciente, se vislumbran los cambios que habría que relacionar con los inicios de la Edad del Hierro y se comprueba su continuidad durante el Período Orientalizante. Si en principio la explotación agropecuaria del lugar puede relacionarse con la obtención de los recursos habituales por una sociedad prehistórica, con el cultivo de la vid, la viticultura y la probable obtención de un vino local en momentos tan antiguos, se explica el cambio y la complejidad de la sociedad occidental desde los primeros siglos del I Milenio a.C., que es exponente de su alto desarrollo particular, en contra de lo que se ha venido preconizando en la última década para dar mayor importancia a la presencia fenicia en Occidente.

\section{REFERENCIAS BIBLIOGRÁFICAS}

Almagro Basch, M. (1957): Las fíbulas de codo del tipo Huelva. Sus tipos y cronología. Cuadernos de Trabajos de la Escuela de Historia y Arqueología de Roma, IX.

Almagro Gorbea, M. (1977): El Bronce Final y el Periodo Orientalizante en Extremadura. Bibliotheca Praehistorica Hispana, XIX. Madrid.

Amo y de La Hera, M. del (1975): Enterramientos en cista de la Provincia de Huelva. Huelva: Prehistoria y Antigüedad, Madrid: 109-182.

Antunes, S.; Deus, M. de; Monge, A.M.; Santos, F.; Arêz, L. Dewulf, J.; Baptista, L.; Oliveira, L. (2012): Povoados abertos do Bronze Final no Médio Guadiana. Sidereum Ana, I1. El río Guadiana en el Bronce Final (J. Jiménez Ávila, ed.), Anejos de AespA. Mérida (Badajoz): 277-308.

Aubet Semmler, M.E. (1998): Prólogo. El tránsito del II al I Milenio a.C. en las cuencas medias de los ríos Tajo y Guadiana: La Edad del Bronce (I. Pavón, ed.), Cáceres.

Belén Deamos, M.; Escacena Carrasco, J.L. (1995): Acerca del Horizonte de la Ría de Huelva. Consideraciones sobre el final de la Edad del Bronce en el Suroeste Ibérico. En Ruiz-Gálvez 1995: 85-113.

Belén, M.; Fernández-Miranda, M.; Garrido, J.P. (1978): Los orígenes de Huelva. Excavaciones en Cabezos de San Pedro y La Esperanza. Huelva Arqueológica, III. Madrid.

BiKaI, P.M. (1978): The Pottery of Tyre. Aris \& Phillips, Warminster.

BiKaI, P.M. (1987): The Phoenician Pottery of Cyprus. A.G. Leventis Foundation. Nicosia. 
Blanco, A.; Luzón, J.M.; Ruzz-MatA, D. (1969): Panorama tartésico en Andalucía Occidental. Tartessos y sus problemas. Barcelona: 119-162.

Blázquez, J.M.; Luzón, J.M.; Gómez, F.; Clauss, K. (1970): Las cerámicas del Cabezo de San Pedro, Huelva. Huelva Arqueológica I. (2a Ed., 1989) Diputación Provincial de Huelva, Huelva.

Blázquez, J.M.; Ruiz-Mata, D.; Remesal, J.; Ramírez, J.L.; Clauss, K. (1979): Excavaciones Arqueológicas en el Cerro de San Pedro (Huelva). Campaña de 1977. Excavaciones Arqueológicas en España, 102: 13-199.

Brandherm, D. (2007): Las espadas del Bronce Final en la Península Ibérica y Baleares. Prähistorische Bronzefunde, Abt. IV, Band 16. Franz Steiner Vrlg., Stutggart.

CAmpos, J.M.; Gómez, F.; Pérez, J.A. (2006): Ilipla-Niebla. Evolución urbana y ocupación del territorio. Col. Arias Montano 80, Servicio de Publicaciones, Universidad de Huelva, Huelva.

Carretero, M.I.; Pozo, M.; Gómez, F.; Ruiz, F.; Abad, M.; González, M.L.; Rodríguez, J.; Cáceres M.A.; Toscano, A.; Baptista, M.A.; Silva, P.; Font, E. (2010): Primeras evidencias de contaminación histórica en el Parque Nacional de Doñana (SO de España). Studia Geologica Salmanticencia, 46(1): 65-74.

Díaz del Olmo, F. (1989): Paleogeografía Tartésica. Tartessos: Arqueología Protohistórica del Bajo Guadalquivir (M.E. Aubet, coord.), Barcelona: 13-23.

Escacena Carrasco, J.L. (1995): La etapa precolonial de Tartessos. Reflexiones sobre el "Bronce" que nunca existió. Tartessos 25 años después (1968-1993). Jerez de la Frontera (Cádiz): 179-214.

Fernández, F.; Ruiz-Mata, D.; SAncha, S. (1976): Los enterramientos en cistas del cortijo de Chichina (Sanlúcar la Mayor, Sevilla). Trabajos de Prehistoria, 33: 351-386.

Fundoni, G. (2009): La relazioni tra la Sardegna e la Peninsola Iberica nei primi secoli del I millenio a.C.: Le testimonianze nuragiche nella Peninsola Iberica. Anales de Arqueología Cordobesa, 20: 11-34.

García Sanjú́n, L. (1999): Los Orígenes de la Estratificación Social. Patrones de Desigualdad en la Edad de Bronce del Suroeste de la Península Ibérica (Sierra Morena Occidental c. 1700-1100 a.n.e/2100-1300 A.N.E.). Oxford.

Gómez Toscano, F. (1998): El final de la Edad del Bronce entre el Guadiana y el Guadalquivir. Servicio de Publicaciones de la Universidad de Huelva. Huelva.

Gómez Toscano, F. (2006): El final de la Edad del Bronce entre el Guadiana y el Guadalquivir. Síntesis históricoarqueológica según las más recientes evidencias. Madrider Mitteilungen, 47: 24-42.

Gómez Toscano, F. (2008): Cerámicas del Bronce Final en Huelva (1200-600 a.C.). Nueva tipología para explicar su amplitud cronológica. Tabona, 16: 85-100.

Gómez Toscano, F. (2009): Huelva en el año 1000 a.C., un puerto cosmopolita entre el Atlántico y el Mediterráneo. Gerión, 27, 1: 33-65.

Gómez Toscano, F. (2012): El Bronce Final en el Bajo Guadiana. Huelva y la resolución de un paradigma. Sidereum Ana, I1. El río Guadiana en el Bronce Final (J. Jiménez Ávila, ed.), Anejos de AespA. Mérida (Badajoz): 309-326.

Gómez Toscano, F. (2013): Contactos con el Mediterráneo Oriental en el Suroeste de la Península Ibérica durante los siglos XIV-VIII a.C. ¿Marinos orientales o fenicios atemporales? Onoba, 1: 79-98.

Gómez Toscano, F. (en prensa): Precolonización Fenicia, Tarsis y Tartesos. Una perspectiva arqueológica a través de los hallazgos de Huelva. Tarsis-Tartesos. Mito, Historia, Arqueología. Actas de Jornadas del Centro de Estudios Fenicios y Púnicos (CEFYP). Universidad Complutense de Madrid y Casa Velázquez. Madrid, 16-18 de abril de 2007.

Gómez Toscano, F.; Campos Carrasco, J.M. (2008): El Bronce Final prefenicio en Huelva según el registro arqueológico del Cabezo de San Pedro. Una revisión cuarenta años después. Complutum, 19: 121-138.

Gómez Toscano, F.; Beltrán, J.M.; Rastrojo, J. (2007): La conformación del sitio arqueológico de Huelva. Procesos naturales y actividad humana. Spal, 16: 155-172.

Gómez Toscano, F.; Fundoni, G. (2011): Relaciones del Suroeste con el Mediterráneo en el Bronce Final (siglos XI-X a.C.), Huelva y la isla de Cerdeña. Anales de Arqueología Cordobesa, 21. Córdoba: 11-34.

Gómez Toscano, F.; Linares, J.A.; De Haro, J. (2009): Fondos de Cabaña del Bronce Final-Orientalizante en la Tierra Llana de Huelva. IV Encuentro de Arqueología del Suroeste Peninsular (J.A. Pérez y E. Romero, eds.), Huelva: 606-647.

GonzÁlez de Canales, F.; Serrano, L.; Llompart, J. (2004): El emporio fenicio precolonial de Huelva (ca. 900770 a.C.). Madrid.

GonzÁlez de Canales, F.; Serrano, L.; Llompart, J. (2009): El inicio de la Edad del Hierro en el Suroeste de la 
Península Ibérica, las navegaciones precoloniales y cuestiones en torno a las cerámicas locales de Huelva. $I V$ Encuentro de Arqueología del Suroeste Peninsular (J.A. Pérez y E. Romero, eds.), Huelva: 648-698.

González, B.; Linares, J.A.; Vera, J.C.; GonzÁLez, D. (2008): Depotfund Zylinderförmiger Idole des 3. Jts. v. Chr. aus La Orden-Seminario (Huelva). Madrider Mitteilungen, 49: 1-28.

Hunt Ortiz, M.A. (2003): Prehistoric Mining and Metallurgy in South West Iberian Peninsula. BAR International Series 1188. Oxford.

Hurtado Pérez, V. (2007): El II Milenio a.n.e. en Andalucía Occidental en la Sierra de Huelva. El nacimiento de la ciudad. La Carmona Protohistórica (M. Bendala, M. Belén, dirs.), Sevilla: 113-138.

Hurtado, V.; García, L.; Hunt, M. (2011): El asentamiento de El Trastejón (Huelva). Investigaciones en el marco de los procesos sociales y culturales de la Edad del Bronce en el Suroeste de la Península Ibérica. Dirección General de Bienes Culturales de la Junta de Andalucía. Sevilla.

Jiménez Ávila, J.; Guerra Millán, S. (2011): El Bronce Final en Medellín: Estudio preliminar del Corte 'SMRO”. Sidereum Ana, I1. El río Guadiana en el Bronce Final (J. Jiménez Ávila, ed.), Anejos de AespA. Mérida (Badajoz): 65-110.

Kristiansen, K.; Larsson, T.B. (2006): La emergencia de la Edad de Bronce. Viajes, transmisiones y transformaciones. Bellaterra, Barcelona.

Lo Schiavo, F. (2009a): I rapporti fra Sicilia e Sardegna nel II millennio a.C. Immagine e immagini della Sicilia e di altre isole del Mediterraneo antico (C. Ampolo, ed.), Vol. 1. Pisa: 401-420.

Lo Schiavo, F. (2009b): The Central Mediterranean: Sardinia. Oxhide Ingots in the Central Mediterranean (F. Lo Schiavo, J.D. Muhly, R. Maddin, A. Giumlia-Mair, eds.), A.G. Leventis Foundation, CNR-Instituto di Studi sulle Civiltà dell'Egeo e del Vicino Oriente. Roma: 225-407.

López CABot, C.; Vera Rodríguez, J.C. (en prensa): Una cabaña orientalizante en el ruedo agrícola de Huelva. Sidereum Ana III. El río Guadiana y Tartessos (J. Jiménez Ávila, ed.), Instituto de Arqueología de Mérida, 19-21 de Septiembre de 2012.

Martínez Fernández, Mª.J.; Vera Rodríguez, J.C. (en prensa): Los enterramientos de la Edad del Bronce del yacimiento de La Orden-Seminario (Huelva). Rituales funerarios y diferenciación sexual en la transición del tercer al segundo milenios cal a.C. en Andalucía occidental. Huelva Arqueológica, 23.

Monge Soares, A. (2005): Os povoados do Bronze Final do Sudoeste na margen esquerda portuguesa do Guadiana: novos dados sobre a cerámica de ornatos brunidos. Revista Portuguesa de Arqueología, 8, 1: 111-145.

PaVón Soldevilla, I. (1998): El tránsito del II al I milenio a.C. en las cuencas medias de los ríos Tajo y Guadiana: La Edad del Bronce. Servicio de Publicaciones de la Universidad de Extremadura, Cáceres.

Ruiz-Gálvez Priego, M.L. (1995): Ritos de paso y puntos de paso. La Ría de Huelva en el mundo de Bronce Final europeo. Complutum Extra, 5. Madrid.

Ruzz-Mata, D. (1979): El Bronce Final -fase inicial- en Andalucía Occidental. Ensayo de definición de sus cerámicas. Archivo Español de Arqueología, 52: 3-19.

RuIz-MATA, D. (1995): Las cerámicas del Bronce Final. Un soporte tipológico para delimitar el tiempo y el espacio tartésico. Tartessos 25 años después (1968-1993). Jerez de la Frontera, Cádiz: 265-313.

Ruiz-Mata, D.; Blázquez, J.M.; Martín de la Cruz, J.C. (1981): Excavaciones en el Cabezo de San Pedro (Huelva). Campaña de 1978. Huelva Arqueológica, V: 149-316.

Ruiz-Mata, D.; Gómez Toscano, F. (2008): El final de la Edad del Bronce en el Suroeste Ibérico y los inicios de la colonización fenicia en Occidente. Contacto cultural entre el Mediterráneo y el Atlántico (siglos XII-VIII ane). La precolonización a debate (S. Celestino, N. Rafel, X.L. Armada, eds.), Serie Arqueológica - II. Escuela Española de Historia y Arqueología de Roma, CSIC. Madrid: 323-353.

Schubart, H. (1971): Acerca de la cerámica del Bronce Tardío en el Sur y Oeste peninsular. Trabajos de Prehistoria, 28, Madrid: 3-32.

Schubart, H. (1975): Die Bronzezeit im Südwesten der Iberischen Halbinsel. Madrider Forschungen, 9. Berlín.

SHaW, J.W. (1998): Kommos in Southern Crete: an Aegean Barometer for East-West Interconnections. Eastern Mediterranean: Cyprus-Dodecanese-Crete 16th-6th cent. B.C. (V. Karageorghis, N. Stampolidis, eds.), Atenas: 2-14.

Torres Ortiz, M. (2008): Los "tiempos" de la Precolonización. Contacto cultural entre el Mediterráneo y el Atlántico (siglos XII-VIII ane). La precolonización a debate (S. Celestino, N. Rafel, X.L. Armada, eds.), Serie Arqueológica - II. Escuela Española de Historia y Arqueología de Roma, CSIC. Madrid: 59-91.

Vera Rodríguez, J.C.; Echevarría Sánchez, A. (2013): Sistemas agrícolas del I Milenio a.C. en el yacimiento de 
La Orden-Seminario de Huelva. Viticultura protohistórica a partir del análisis arqueológico de las huellas de cultivo. Patrimonio cultural de la vid y el vino (S. Celestino, J. Blánquez, eds.), Madrid: 95-106.

Vera, J.C.; Linares, J.A.; Armenteros, Ma..J.; GonzÁlez, D. (2010): Depósitos de ídolos en el poblado de La Orden-Seminario de Huelva: Espacios rituales en contexto habitacional. Ojos que nunca se cierran. Ídolos en las primeras sociedades campesinas (C. Cacho, R. Maicas, E. Galán, J.A. Martos, coords.), Museo Arqueológico Nacional. Madrid: 199-242.

VilaÇA, R.; Jiménez, J.; Galán, E. (2012): El poblado de Los Concejiles (Lobón, Badajoz) en el contexto del Bronce Final del Guadiana Medio. Sidereum Ana, I1. El río Guadiana en el Bronce Final (J. Jiménez Ávila, ed.), Anejos de AespA. Mérida (Badajoz): 125-165. 